PontIFícIa UNIVERSIDADE CATÓLICA dO RIO DE JANEIRO

Consumo em Papelarias: Atributos que Influenciam o Processo Decisório de Compra em Estabelecimentos Varejistas do Rio de Janeiro

Caroline Albergaria

Trabalho de Conclusão de Curso

Centro de CIÊnCIAS SOCIAIS - CCS

DePARTAMENTO de AdMINISTRAÇÃo

Graduação em Administração de Empresas 
Rio de Janeiro, Dezembro de 2017. 
Caroline Albergaria

\section{Consumo em Papelarias: Atributos que Influenciam o Processo Decisório de Compra em Estabelecimentos Varejistas do Rio de Janeiro}

Trabalho de Conclusão de Curso, apresentado ao programa de graduação em Administração da PUC-Rio como requisito parcial para a obtenção do titulo de graduação em Administração. 
"Atender às expectativas do cliente irá apenas satisfazê-los; excedê-las irá encantá-los" (Philip Kotler). 


\section{Agradecimentos}

Primeiramente à minha irmã por ser minha maior amiga e companheira.

Aos meus pais, Jorge e Isabel, por tornarem minha trajetória possível e por acreditarem sempre em mim.

Aos meus avós: Jorge, Guida, Carlos e sua esposa Théa, que sempre estiveram torcendo por mim e me apoiando.

Às minhas avós, Lourdes e Catarina, pelo amor e confiança nas minhas conquistas.

Aos meus tios, Paulo, Ana e Bianca, pelo carinho e auxílio espiritual.

À minha afilhada, Sophia, pela compreensão nesses últimos meses. À sua mãe, Beatriz, pela amizade e companheirismo.

Por fim, agradeço à professora Bárbara Levy, pela orientação e paciência nessa etapa, para elaboração do presente trabalho. 


\title{
Resumo
}

Albergaria, Caroline Monteiro de. Consumo em Papelarias: Atributos que Influenciam o Processo Decisório de Compra em Estabelecimentos Varejistas do Rio de Janeiro. Rio de Janeiro, 2017. 39 p. Trabalho de Conclusão de Curso - Departamento de Administração. Pontifícia Universidade Católica do Rio de Janeiro.

$\mathrm{O}$ varejo é uma das atividades mais importantes da economia mundial. $\mathrm{Na}$ busca pelo sucesso de suas vendas, deve-se entender o comportamento de seu público alvo. O seguinte estudo oferece essa análise aplicada diretamente ao setor de papelarias tratando, principalmente, dos aspectos motivacionais e atributos mais relevantes na ótica do consumidor para esse segmento de comércio.

Palavras-chave: Marketing; Varejo; Comportamento do Consumidor; Decisão de compra; Papelarias; Comércio.

\section{Abstract}

\begin{abstract}
Albergaria, Caroline Monteiro de. Purchase in Stationery: Attributes that Influence the Decision Process of Purchase in Retail Establishments of Rio de Janeiro. Rio de Janeiro, 2017. 39 p. Trabalho de Conclusão de Curso Departamento de Administração. Pontifícia Universidade Católica do Rio de Janeiro.
\end{abstract}

Retailing is one of the most important activities of the world economy. In the quest for the success of your sales, must be understanded the behavior of your target audience. The following study offers this analysis applied directly to the stationery industry, mainly dealing with the most relevant motivational aspects and attributes in the consumer's perspective for this commerce segment..

Keywords: Marketing; Retail; Consumer Behavior; Buying decision; Stationery stores; Commerce. 


\section{Sumário}

1. Tema e problema de estudo 1

1.1. Introdução ao tema e problema do estudo 1

1.2. Objetivo do estudo 3

1.3. Objetivos Intermediários do Estudo 3

1.4. Delimitação e foco do estudo 3

1.5. Justificativa e relevância do estudo 4

2. Revisão de Leitura 6

2.1. Comércio Varejista 6

2.1.1. Principais características $\quad 7$

2.1.2. Contexto brasileiro 8

2.1.3. Setor de papelarias 9

2.2. Consumidor 9

2.2.1. Definição 10

$\begin{array}{ll}\text { 2.2.2. Comportamento } & 10\end{array}$

2.3. Compra e consumo 11

2.3.1. Motivação 11

2.3.2. Processo decisório 13

2.4. Consumidor de Varejo 15

$\begin{array}{ll}\text { 2.4.1. Ambiente brasileiro } & 16\end{array}$

3. Metodologia de Pesquisa 18

3.1. Tipo de pesquisa utilizada 18

3.2. Seleção dos informantes 18

3.3. Procedimentos e instrumentos de coleta de dados utilizados 19

3.4. Processo de análise de dados 20

$\begin{array}{ll}\text { 3.5. Limitações do estudo } & 21\end{array}$

4 . Descrição e análise dos resultados 22

4.1. Perfil dos participantes 22

4.2. Conceito e funções de papelarias na visão do consumidor 22 
4.3. Motivações para consumo 24

4.4. Atributos percebidos $\quad 27$

4.4.1. Identificação 28

4.4.2. Grau de importância 30

5 . Conclusão 33

5.1. Sugestões e recomendações para novos estudos 34

6. Referências Bibliográficas 36

Apêndice I $\quad 40$

\section{Lista de Figuras}

Figura 1: Vendas segundo grupo de atividades pela PMC .............................. 2

Figura 2: Funções do administrador de varejo................................................ 7

Figura 3: Etapas da tomada de decisão do consumidor adaptado ao setor de

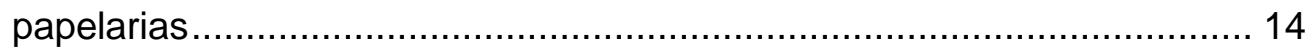

Figura 4: Razões de preferência do consumidor brasileiro por lojas físicas....... 16

Figura 5: Prática de web-rooming pelo consumidor brasileiro ......................... 17

Figura 6: Relação com o varejista brasileiro via rede social ........................... 17

Figura 7: Motivos para visitar uma papelaria ................................................. 25

Figura 8: Relação entre o tamanho do varejo e a preferência do consumidor ... 28

Figura 9: Relação tipo de varejo $\mathrm{x}$ tamanho do varejo $\mathrm{x}$ preferência do

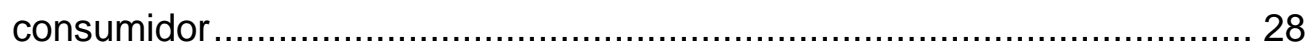

Figura 10: Atributos para a maioria dos consumidores de papelaria ................ 30

Figura 11: Hierarquização dos atributos identificados pelos consumidores ....... 31

Figura 12: Proposta exemplo de modelo de Fishbein para estudos futuros....... 35 


\section{Tema e problema de estudo}

\subsection{Introdução ao tema e problema do estudo}

O setor de varejo é caracterizado, em geral, por direcionar-se ao consumidor final. Ele também representa a última etapa do processo de distribuição de produtos e serviços sendo o estágio no qual ocorre o contato das unidades de negócio diretamente com os clientes (MATTAR, 2011).

Retratado principalmente pelas tradicionais lojas físicas, o varejo se apresenta por diversos canais de distribuição. Hoje, entretanto, impactado pelas evoluções tecnológicas, o comércio praticado pela internet também simboliza destaque nesse setor.

A pesquisa Total Retail de 2016, realizada pela PricewaterhouseCoopers, indica que, com o objetivo de se posicionar adequadamente às circunstâncias, o varejista precisa diferenciar seus investimentos e atualizar certos paradigmas. Essas diversificações dependem da aplicação de estudos distintos às suas estratégias.

Os varejistas, ainda de acordo com informações da PricewaterhouseCoopers de 2016, constituem o comércio, que é um modelo de negócio poderoso e adaptável e que já existe e funciona por séculos, representando uma das práticas mais importantes da economia mundial. Diversas atividades são responsáveis por compor a natureza do comércio, seja ele classificado como varejista ou como varejista ampliado.

A estrutura do comércio é aqui retratada seguindo as premissas da Pesquisa Mensal de Comércio, PMC, (realizada todos os anos e divulgadas pelo IBGE), pela integração de oito atividades de varejo e duas de varejo ampliado. A análise separada dessas atividades possibilita um direcionamento mais refinado sobre o comércio.

A partir destes compostos apresentados (vide figura 1) e considerando o ambiente de maior conforto para a autora devido a experiências familiares prévias com o universo de papelarias, é proposto um estudo sobre essa linha específica de varejo. Segundo dados do Sebrae (2017) esse segmento, fundamentalmente planejado para se encaixar apenas na sexta atividade 
exposta na figura 1 , hoje, pode ser considerado como integrado também pelas sétima e oitava atividades.

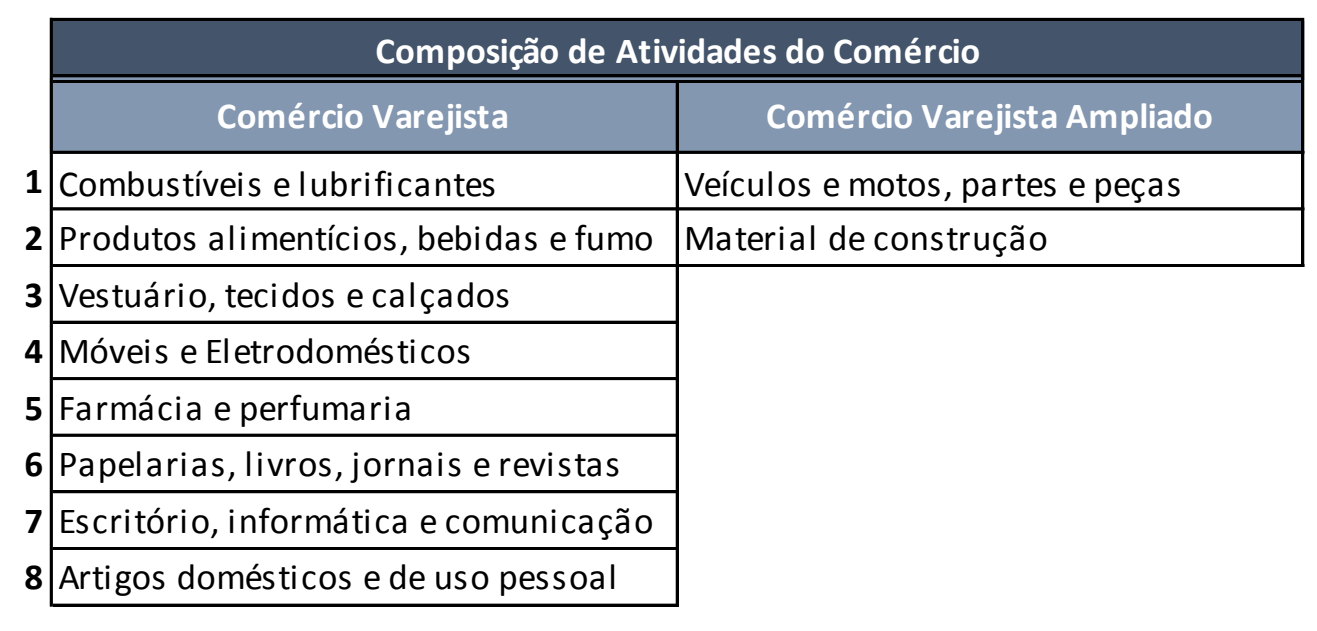

Figura 1: Vendas segundo grupo de atividades pela PMC

Fonte: adaptado do IBGE, 2017

As papelarias, assim como a maioria dos segmentos de comércio, em datas comemorativas como, por exemplo, Natal e celebração de dia das mães e pais, se beneficia da sazonalidade como motivação extra para realização de compras. É válido, porém, ressaltar o grande peso desta no começo do ano letivo de colégios, creches e até faculdades especialmente para os comerciantes e consumidores de papelarias, conhecido como período de 'volta às aulas'.

No começo do ano, a aquisição de materiais escolares torna-se uma prioridade para quem está matriculado no colégio, pois devem atender as listas de compra solicitadas. Grande parte dos consumidores de listas de material escolar no Brasil é formada por pais de crianças e adolescentes matriculados em colégios. Dados do Fecomércio RJ/Ipsos, de 2015, apontam que 39\% das pessoas afirmam comprar material escolar no início dos anos para os seus filhos.

Para os comerciantes e empresários ligados ao setor de comércio de papelarias, porém, entender o comportamento de seu consumidor não só nesse período, mas ao longo do ano é primordial e possibilita melhor planejamento de suas estratégias para diferentes ocasiões.

Estudos dessa natureza, portanto, podem ser elaborados de diferentes maneiras e uma delas é a partir da identificação dos atributos importantes, sob a ótica do consumidor, para o processo decisório de compra. 
Com base nas informações apresentadas, busca-se, por fim, responder a seguinte questão: quais são os atributos que influenciam o processo decisório de compras experimentado pelos consumidores do varejo de papelarias?

\subsection{Objetivo do estudo}

O propósito do presente trabalho é identificar quais os principais atributos que interferem na atuação do consumidor quanto ao processo de tomada de decisão de compra em papelarias.

\subsection{Objetivos Intermediários do Estudo}

Para aprofundar o estudo sobre o consumidor do comércio varejista no segmento de papelarias e alcançar a meta final, esse artigo abordará os seguintes objetivos intermediários:

- Percepção do conceito de papelaria sob a ótica do consumidor;

- Análise das principais motivações para compra de itens de papelaria;

- Definição da localização comercial considerada mais adequada nesse setor;

- Identificação dos atributos que, a partir dessas motivações, impactam na tomada de decisão do consumidor de papelarias;

- Medição do grau de importância dos atributos detectados;

\subsection{Delimitação e foco do estudo}

O estudo tem como foco principal o comércio varejista e é aplicado para o comportamento das pessoas como consumidoras deste mercado. A análise está delimitada, portanto, a um segmento em particular que, conforme apresentado anteriormente, será o de papelarias.

Neste artigo, compreende-se a definição mais atual do SEBRAE, que considera como papelarias estabelecimentos comerciais que ofereçam itens do setor tradicional, além de material de escritório, acessórios de informática e mercadorias de bazar, bem como artigos para presentes e/ou de uso rotineiro.

Não estão incluídos dados sobre os consumidores de papelarias atacadistas e nem de outros estabelecimentos de comércios aplicados a outras atividades nessa análise. Mesmo entendendo que possam ser frequentadas 
empresas de outra especialização que ofereçam soluções similares ou até as mesmas, pelos clientes.

O estudo foi aplicado com o intuito de permitir uma análise mais incisiva dos dados obtidos, somente a pessoas que praticam o processo de consumo em varejos do segmento de papelarias em estabelecimentos físicos, localizados obrigatoriamente no Rio de Janeiro.

\subsection{Justificativa e relevância do estudo}

Com certa frequência, o mundo tem passado por inovações em diferentes âmbitos de atuação. Segundo dados da PricewaterhouseCoopers (2016), por exemplo, as evoluções causadas ao contexto tecnológico resultam em uma facilidade cada vez maior ao acesso à informações, aumentando as expectativas de vários stakeholders de uma empresa, incluindo seus clientes.

A receita de um estabelecimento é gerada a partir do dinheiro gasto nela por seus clientes e a realização de um estudo sobre o comportamento do consumidor é importante na preparação de estratégias de marketing e operacionais das organizações que, consequentemente, auxilia no atendimento de suas metas financeiras.

A identificação dos atributos influentes sobre o processo de decisão de compra de um indivíduo pode ser utilizada de inúmeras maneiras pelas empresas. A atribuição de informações e contextos mais atuais para essa análise também contribui para sua valorização, seja habilitando estudos comparativos com dados do passado, ou em sua elaboração no futuro.

Assumindo o objetivo do estudo como alcançado, esses atributos identificados possibilitam que se iniciem pesquisas de outras naturezas. A utilização dessas informações pelas empresas permite mudanças em suas estratégias, viabilizando melhoras nas experiências de compras para os clientes e, logo, nos resultados da organização.

Finalmente, com base na avaliação destes e de outros impactos sofridos pelo ambiente inserido, a análise feita sob a visão do comércio varejista se mostra relevante, principalmente ao considerar que o segmento de varejo no Brasil representa $20 \%$ do PIB do país, segundo dados divulgados em 2016, pela SBVC (Sociedade Brasileira de Varejo e Consumo).

Compreender o comércio de papelarias em especial, apesar da escolha do segmento por experiência pessoal da autora, é interessante também para auxiliar a composição de um banco de dados mais abrangente sobre esse setor 
uma vez que não são encontrados disponíveis muitos estudos aplicados para esse segmento. 


\section{Revisão de Leitura}

Para atingir a compreensão do tema abordado no estudo, é apresentada a seguir, uma revisão de leitura sobre o processo de decisão de compra experimentado pelos consumidores, incluindo 0 entendimento de suas motivações de consumo. Elabora-se, também, um panorama sobre o setor varejista de forma geral e no cenário atual brasileiro.

$\mathrm{Na}$ busca pelo alcance dessa meta, é preciso descrever e, igualmente, interpretar a importância do mercado de varejo no país, bem como seu desenvolvimento e seus principais aspectos. Para isso, procura-se retratar o perfil do consumidor de varejo no Brasil de modo a permitir estabelecer uma conexão entre ele e o mercado envolvido com o universo de papelarias. Em resumo, é abordada a conceituação de varejo e são apresentadas suas características em contextualização com a população brasileira.

A compreensão das pessoas que consomem nesse segmento de comércio, portanto, é feita sobre a concepção generalizada de mercado consumidor, incluindo a definição do processo de consumo para teorizar o comportamento dos indivíduos quando nele e seu desempenho ao atuar na decisão de compra. Por fim, busca-se aplicar os principais aspectos desse segmento no setor de papelarias.

\subsection{Comércio Varejista}

Kotler (2000) conceitua varejo como o desenvolvimento das vendas de bens ou serviços, que são oferecidos de forma direta ao consumidor final para atender suas necessidades de uso pessoal. $O$ autor também afirma que varejo, em seu escopo de atuação, envolve outras atividades do processo de consumo que vão além do ato de compra em si.

O varejo caracteriza-se, portanto, por ser o último estágio do processo de distribuição de bens ou serviços, alcançando o consumidor final. Ele engloba um conjunto de atividades de negócios que agregam valor aos produtos oferecidos aos clientes. (MATTAR, 2011). 
Berry (1986) coloca os negócios de varejo como sendo negócios de serviços. A explicação do autor é que, apesar das diferenças entre empresas varejistas e empresas de serviço, mesmo os varejos que utilizam o sistema de auto serviço são altamente compostos de serviços.

Descobrir como os fatores que compõem um ambiente de varejo podem ser combinados de forma ótima a fim de proporcionar para os clientes experiências agradáveis e marcantes é possível e deve fazer parte do escopo do varejista. (PECORARO, UUSITALO, 2014)

\subsubsection{Principais características}

Segundo Las Casas e Garcia (2007), o papel do varejo é, principalmente, o de realizar intermédio das mercadorias entre o fabricante/atacadista e os clientes, disponibilizando os produtos em lojas ou em outros meios de distribuição final para alcance do consumidor.

Como canal de distribuição, o varejo pode ser classificado em até treze categorias e, para aplicação do estudo, seguem as definições de três delas:

- Lojas especializadas: formadas por varejistas independentes, oferecem uma linha única e produtos limitados;

- Lojas independentes: apresentam administração simples e atendimento personalizado, onde o proprietário ou gerente tem contato direto com os clientes;

- Lojas de variedades: estabelecimentos com variedade muito extensa de mercadorias e, em geral, de baixos valores.

Independente da categoria de varejo seguida é essencial que haja estruturação de suas funções básicas, pois são elas que vão delinear quais as variáveis controláveis do estabelecimento. (LAS CASAS, 2004).

\begin{tabular}{|l|}
\hline \multicolumn{1}{|c|}{ Funçães Básicas do Varejo } \\
\hline \hline Obtenção de mercadorias por meio de compras \\
\hline Formação de preço dessas mercadorias \\
\hline Promoção das mercadorias por meio de propaganda ou display \\
\hline Oferta de serviços que valorizem a distribuição das mercadorias \\
\hline Venda pessoal das mercadorias \\
\hline Controle, logístico e de estoque, das mercadorias \\
\hline
\end{tabular}

Figura 2: Funções do administrador de varejo

Fonte: adaptado de Las Casas, 1992 
Ainda segundo Las Casas e Garcia (2007), para a conclusão destas funções básicas, o varejo deve determinar seu portfólio de produtos, sua oferta de serviços, os métodos de comunicação e os meios de distribuição que serão utilizados.

Entretanto, apenas a seleção apropriada desses elementos para o plano de negócios não é capaz de garantir o sucesso das operações varejistas, que dependem, ainda, do planejamento da interação adequada entre estes fatores.

\subsubsection{Contexto brasileiro}

A implementação do varejo aconteceu no Brasil a partir de modelos que atingiram resultados positivos no exterior e foi se adaptando conforme necessário.

O varejo era concentrado, principalmente, em centros comerciais de rua. $O$ surgimento de shoppings centers no país obteve sucesso e os antigos centros comerciais foram, em geral, esquecidos, passando a atender mais aos consumidores de baixa renda. (MATTAR, 2011).

Com o crescimento do mercado produtor e de diversos setores do varejo, consequentemente, conforme é apontado por Serrentino (2007), o setor buscou se diferenciar por meio de vantagens competitivas aplicadas a sua oferta de produtos.

Segundo Oliveira (1999), foi na década de 90, após o Plano Real ampliar o poder aquisitivo da população e o CDC (Código de Defesa do Consumidor) formalizar os direitos do consumidor, que as redes de varejo passaram a se preocupar mais com a qualidade percebida pelo público, resultando no aumento do número de segmentos das atividades ofertadas, com o objetivo de facilitar o alcance da satisfação dos clientes.

Definido seu segmento, o varejista passa a se preocupar com suas estratégias de aumento da competitividade, com base na adoção de uma oferta de diferenciação que atenda ao seu plano de negócios e a segmentação estabelecida. (DELOITTE; TOUCHE e TOHMATSU, 2008).

De acordo com Mattar (2011), é certo afirmar que o modelo de varejo é, em geral, aceito pelo consumidor brasileiro, porém, em uma rápida análise sobre a cultura econômica e política no país deve-se observar que o cenário é desafiador.

O excesso de regulamentação imposta, a alta carga fiscal cobrada e a volatilidade da taxa de câmbio influenciam o ambiente do brasileiro, em geral de 
forma negativa para o varejista e, portanto, para o consumidor. (PricewaterhouseCoopers, 2016).

\subsubsection{Setor de papelarias}

As papelarias, em geral, segundo definição do SEBRAE (2017) são vistas como estabelecimentos que comercializam papel e material escolar, apresentando um portfólio de mercadorias que se encaixa na sexta atividade do comércio varejista (vide Figura 1).

Atualmente, entretanto, o perfil do ambiente deste comércio, ainda de acordo com informações do SEBRAE (2017) ostenta um visual diferenciado, com ofertas de serviços e de segmentos de produtos mais diversificadas. Tais mudanças foram incorporadas no cenário brasileiro na década de 90, para reverter a concorrência com supermercados que, nessa época, passaram a vender material escolar.

O setor, então, passou a incluir um novo modelo de negócios, conhecido como papelarias de luxo ou "boutiques de papel", mais propagado nos dias de hoje, que se caracteriza por lojas com maior foco na decoração e grande variedade de produtos com design especial, além dos tradicionais artigos oferecidos em uma papelaria tradicional.

\subsection{Consumidor}

Um dos principais objetivos de marketing, segundo Drucker (1973) é conhecer e compreender tão bem o cliente de forma que o produto ou serviço sirvam-se e se vendam por conta própria, tornando o processo supérfluo.

De acordo com Solomon (2016), durante a juventude, as pessoas adquirem habilidades, conhecimentos e atitudes relevantes para estabelecer sua atuação no mercado, resultando em sua formação como consumidor. A criação da definição deste, conforme apontado por Drucker (1973) deve ser a primeira tarefa de uma empresa na busca por concluir suas vendas.

As empresas existem para satisfazer as necessidades percebidas de um indivíduo ou de outra organização por meio da oferta de soluções com valor agregado que atendam suas necessidades. Apresentadas em forma de produtos e/ou serviços, essas soluções são fornecidas a partir das trocas entre as duas partes interessadas e é na influência sobre essas trocas que o conceito de marketing é fundamentado. (KOTLER e KELLER, 2012). 
Só são capazes de atingir essa meta, as organizações que compreendem os hábitos e características dos indivíduos ou organizações que usarão o que estão tentando vender (SOLOMON, 2016).

\subsubsection{Definição}

Com base nessas evidências, é necessária, então, a criação de debates sobre o comportamento dos consumidores e, para isso, primeiramente, definilos. Assim, Sheth, Mittal e Newman (2001) caracterizam consumidor como um indivíduo em contato com uma organização que comercializa serviços ou mercadorias e que, por fim, desempenha um papel de atuação no processo de consumo desses bens.

Nas definições de Blackwell et. Al. (2008), as atividades exercidas pelas pessoas quando estão adquirindo e dispondo-se de produtos e serviços, formam um mercado habilitado para executar o processo de consumo.

\subsubsection{Comportamento}

Conceitualmente, o processo de consumo inclui as questões e situações vividas pelos clientes nos momentos anteriores, simultâneos e posteriores aos estágios que formam os métodos de decisão de compra de um produto ou serviço, em forma de bem de consumo. (SOLOMON, 2016)

De acordo com Richers (1984), esse objeto de análise (processo de consumo) é definido pela combinação das atividades mentais e emocionais experimentadas pelos consumidores ao buscar produtos ou serviços que satisfaçam suas necessidades e/ou desejos.

Com a intenção de descobrir como agir sobre os aspectos e motivações que englobam a escolha final feita por um consumidor, o estudo do consumo leva, consequentemente, à análise do comportamento das pessoas englobadas nesse processo.

É fundamental, assim, que se tenha o conhecimento do conceito de marketing, dado pela orientação dos consumidores. Oficialmente, esse conceito possui a realização da satisfação dos clientes para solução de seus objetivos como definição. Tal solução tem base na escolha do produto a ser produzido, decisão essa determinada, não pelas empresas, nem pelo governo e sim, pelo comportamento de seu público-alvo, seu potencial consumidor. (KOTLER, 2000). 
O comportamento do consumidor pode ser descrito como um processo flexível de acordo com a conjuntura dos ambientes inseridos. Furtado et. Al (2011) pontua que as ações do comprador são influenciadas por interferências na forma com que os fatores ambientais são relacionados circunstancialmente e se apresentam no desempenho do processo de compra.

Com o efeito desses impactos refletidos em seu comportamento é que o consumidor realiza sua decisão de compra.

\subsection{Compra e consumo}

Em relação ao processo de compra, Kotler (2000) evidencia esta atividade como designada pela troca ou transação de bens entre empresas e consumidores, ocorridas ao se entender como resultado desta uma situação melhor do que a constatada anteriormente para as duas partes.

É fato que as trocas que ocorrem entre consumidores e empresas não se limitam, somente, ao ato da compra em si (AAKER, 1996; KAPFERER, 1997; ELLIOT; WATTANASUWAN, 1998). Deve-se levar em consideração a existência de diferentes formas de interação dos dois lados e que, quando aplicáveis, acontecem também antes e/ou depois da aquisição de um produto ou serviço.

Ressalta-se aqui que as empresas não detém o poder de criar necessidades. Suportado por Solomon (2016), no que diz respeito ao marketing, devem trabalhar na criação e transmissão de uma mensagem adequada com intuito de causar efeitos na forma como as etapas, durante o processo de consumo, são vivenciadas direcionando a maneira com que seus consumidores são motivados a satisfazer essas necessidades.

É importante que primeiro se procure compreender as principais motivações e o processo de decisão de compra, para tornar possível o estabelecimento de uma aplicação estratégica sobre o comportamento do consumidor. Comportamentos e hábitos refletem aspectos cognitivos, emocionais, econômicos e psicológicos do ambiente e ajudam a na formação da decisão de compra das pessoas. (SCHIFFMAN E KANUK, 2009).

\subsubsection{Motivação}

Necessidades são comuns a todas as pessoas. O que difere a necessidade de cada consumidor é o desejo da forma como atendê-la e as motivações que as geraram. 
O consumidor, então, passa pelo processo decisório, adquirindo (ou não) a opção que lhe apresenta maior chance de satisfação. Partindo desses pressupostos, o desenvolvimento de estratégias que influenciam os consumidores, por parte da empresa, durante este processo é facilitado pelo conhecimento e utilização dos motivos que justificam o consumo. (BLACKWELL, et. $A L, 2008)$

Segundo Solomon (2016), motivação, em geral, se refere ao conjunto de processos que fazem as pessoas se comportarem como elas se comportam. Busca-se, portanto, utilizar as características do ambiente e do contexto nos quais o consumidor está inserido para alcançar a melhor forma de atuar sobre suas motivações.

Aplicado especialmente ao processo de compra, Churchill (2000) diz que essas motivações podem ser influenciadas por diversos fatores, que podem ser classificados como externos (do ambiente: sociais, culturais, psicológicos e pessoais) ou internos (do indivíduo). Tais fatores causam impactos principalmente quando aplicados no marketing das empresas sobre seus compostos principais (produto, preço, praça e promoção).

O produto/serviço ou oferta em geral, deve buscar alcançar êxito ao proporcionar valor e satisfação para o comprador-alvo. Esse comprador escolhe entre diferentes propostas aquela que lhe parece agregar maior valor em relação ao seu consumo. (KOTLER, 2000)

Considerando os valores atribuídos aos produtos, Maslow (1970), apresentou a hierarquia das necessidades. Nesta teoria, as necessidades são caracterizadas de acordo com os principais aspectos que as motivam e estão dispostas em forma de uma hierarquia medida pela urgência dessas necessidades.

Segundo Solomon (2016), essa teoria implica que os consumidores valorizam diferentes atributos, dependendo do que eles têm disponível no momento. O autor também afirma, porém, que se deve entender que cada indivíduo pode ter diferentes prioridades, não comum a todas as pessoas, em relação a seus problemas, necessidades e desejos.

Kotler e Keller (2000) sobre esse tópico apresentam, também, a teoria de Freud que conclui que ninguém chega a compreender por completo suas 
próprias motivações, pois a maneira com que os consumidores formam seu comportamento é, em geral, inconsciente.

Os aspectos motivacionais de compra, portanto, tem relação direta com o tipo de necessidade a ser sanada, que pode ser funcional ou emocional, respectivamente categorizada em utilitária ou hedônica, e com as características pessoais e culturais do consumidor. Pode-se afirmar que necessidades utilitárias tem ênfase em objetivos tangíveis oferecidos pelos bens de consumo, enquanto que hedônicas são subjetivas e satisfazem desejos de entusiasmo, autoconfiança ou fantasia. (SOLOMON, 2016).

Para motivação utilitária, que deve acontecer com um objetivo específico, Hui e Bateson (1991) trazem o exemplo da compra de mantimentos, ou seja, por motivos utilitários as pessoas devem consumir em supermercados em algum momento, gostando ou não da experiência.

Por outro lado, razões hedônicas independem da meta que se deseja alcançar, normalmente não estão vinculadas à obrigações e podem estar relacionado ao desejo de interagir socialmente (BAKER e WAKEFIELD, 2012).

Como dito por Holbrook e Hirshman (1982) o consumo hedônico acontece como resultado de uma experiência prazerosa, ocorrida nas circunstâncias em que o consumidor se encontra. Segundo ele, para os indivíduos no consumo, quando por razões hedônicas, o que menos importa é o produto em si.

Entender a motivação e seus atributos principais na forma como eles atuam sobre o indivíduo que experimenta o processo de compra, pode auxiliar no planejamento das empresas de como agir sobre cada etapa deste processo. $\mathrm{Na}$ busca por direcionar a decisão do consumidor, as empresas devem tentar aplicar os aspectos motivacionais de modo a intervir nas decisões resultantes dessas etapas.

\subsubsection{Processo decisório}

Conforme estabelecido por Solomon (2016), todas as decisões de compra a serem tomadas tem o propósito primordial de responder a um problema reconhecido pelo consumidor.

Dependendo dos aspectos que formam o escopo da questão identificada a ser resolvida, a decisão de consumo relacionada pode ser categorizada como: cognitiva (racional), habitual (rotineira) ou afetiva (emocional) e altera a maneira como o consumidor se sente impactado por ela e, consequentemente, o tipo de motivação ao qual está exposto. 
A decisão de compra, quando por meio de um processo racional, pode ser separada em etapas para ser mais bem entendida. São inúmeros os elementos causadores de impactos sobre o processo de compra, que segundo os autores Blackwell et. Al. (2000) podem ser experimentados durante essas cinco etapas vivenciadas pelos consumidores.

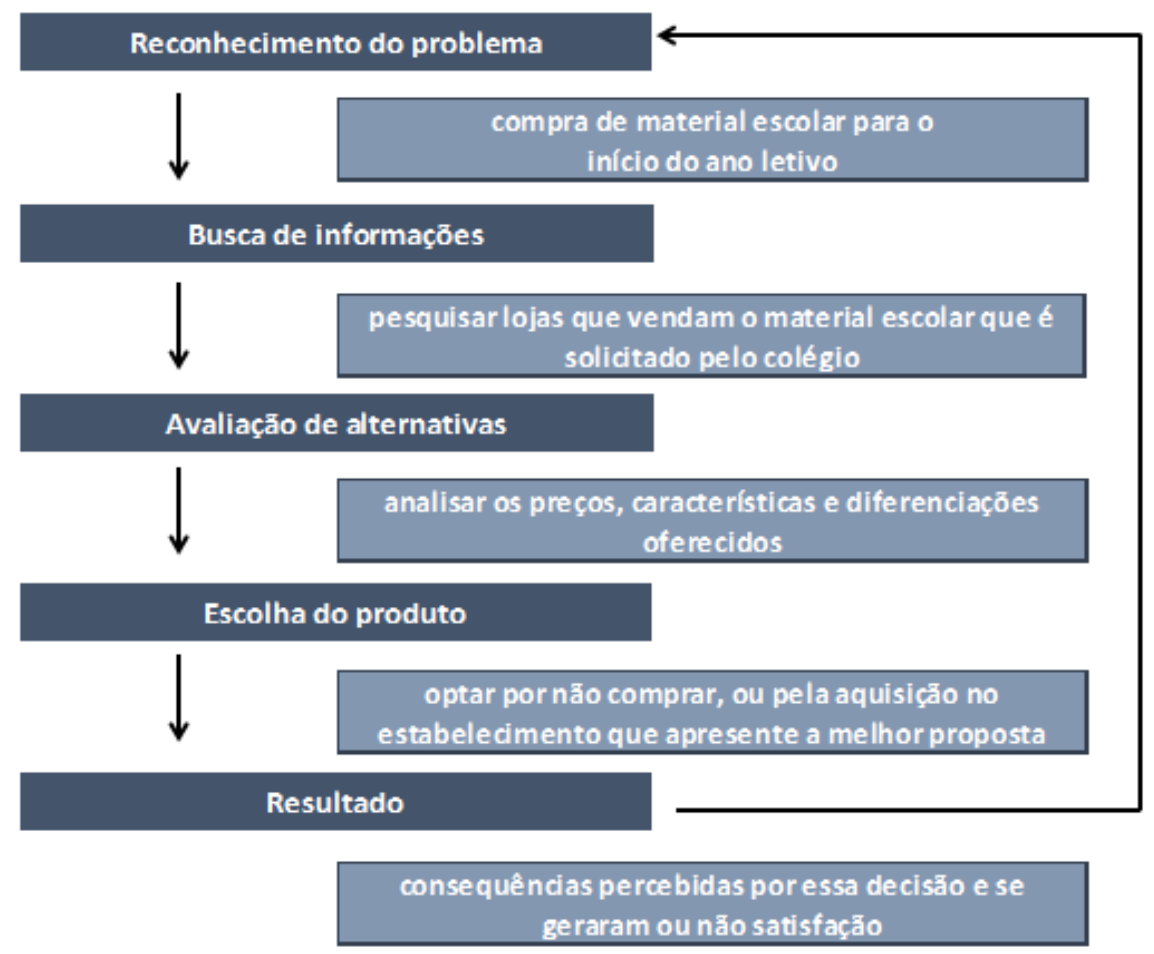

Figura 3: Etapas da tomada de decisão do consumidor adaptado ao setor de papelarias Fonte: adaptado de Solomon, 2016.

Uma vez percebido o problema, cria-se uma necessidade: a de respondêlo. Para isso é indispensável a busca por informações que possibilitem a escolha da melhor solução para este. Nessa etapa, referências internas (do indivíduo) e ambientais (externas) podem começar a agir sobre a motivação da decisão do consumidor. (ENGEL; et. Al, 2005).

Assim, permite-se estabelecer as principais alternativas capazes de resolver a necessidade em questão. Gertner e Diaz (1999) afirmam que a procura por alcançar benefícios utilitários se relaciona com o propósito da busca de informações e leva à identificação dos produtos (ou serviços) ideais para satisfação do problema percebido. 
A partir das alternativas constatadas, se realiza uma comparação e avaliação das opções para que se opte pela considerada como melhor escolha para consumo. Assim, conforme é dito por Kotler (2000), os fabricantes e fornecedores devem presumir que o comprador admira como as mercadorias são produzidas e ofertadas para que possa, então, analisar sua qualidade e seu desempenho.

Sob a ótica de Mowen e Minor (2003), é principalmente nessa etapa do processo de consumo que os atributos motivacionais percebidos interferem na decisão de compra. Com base nos valores dos bens de consumo avaliados de acordo com os diversos aspectos que são atribuídos a eles cabe ao consumidor decidir por realizar a compra daquele que considera como de maior valor. (KOTLER, 2000).

É nesse momento que se seleciona qual mercadoria adquirir, além de quando e onde comprá-la. Caso os aspectos classificados como importantes pelo consumidor sejam manifestados de maneira inadequada ou não sejam percebidos nesta etapa de avaliação de alternativas, o resultado pode contar, também, com a não realização da compra. (ENGEL; et. Al., 2005)

Uma vez em que o produto ou serviço é consumido, o comprador está apto para descrever a sensação que foi obtida por meio dessa experiência. Essa sensação, que pode ser de satisfação ou não e é determinada pelo consumidor, dependendo do tipo de motivação englobada nesta decisão e pode influenciar também na velocidade e/ou maneira com que se executa o descarte do produto obtido. (ENGEL; et. Al., 2005).

\subsection{Consumidor de Varejo}

Conforme dito anteriormente por Solomon (2016), compreende-se como consumidor uma pessoa que identifica uma necessidade ou desejo, realiza o processo de compra e, caso aplicável, o descarte. Segundo Kotler e Keller (2000), essa pessoa, quando aplicada ao varejo, realiza o processo de compra na etapa final da cadeia de distribuição de um produto ou serviço e é chamada de consumidor final.

Ainda de acordo com Solomon (2016), esse consumidor, que representa um indivíduo, organização ou grupo, avalia as situações anteriores, simultâneas ou posteriores a uma compra. Ao estar em contato com o comércio feito em forma de varejo, entretanto, tem como foco principal de sua análise as características percebidas durante o processo de consumo experimentado. 


\subsubsection{Ambiente brasileiro}

No Brasil, assim como na maioria dos países, os consumidores podem ser atendidos por diversos canais de distribuição disponíveis pelo varejo. Além de lojas físicas, existem as vendas feitas por telefone, diretas, por catálogo e pela internet, além de outras opções menos utilizadas. (MATTAR, 2011)

Solomon (2016) conceitua que os consumidores, durante o processo de consumo, estão sujeitos à sensações causadas por estímulos básicos do ambiente. Essas sensações são efeitos do contexto e tem impacto sobre a experiência do consumidor que, a partir dela, passa pelo processo de aprendizagem, influenciando sua forma de agir no futuro.

Cada canal de distribuição pode oferecer diferentes formas de manifestar essas sensações, de acordo com o que considerar mais adequado para o meio escolhido. Ainda segundo Mattar (2011), atualmente os canais mais utilizados para vendas, pelas empresas e mais procurados pelos clientes são a distribuição por estabelecimentos físicos e pela internet.

A partir de uma análise de dados divulgados pela PwC (2015), apesar da globalização e do avanço tecnológico, a preferência dos consumidores brasileiros ainda é pela compra feita em lojas físicas.

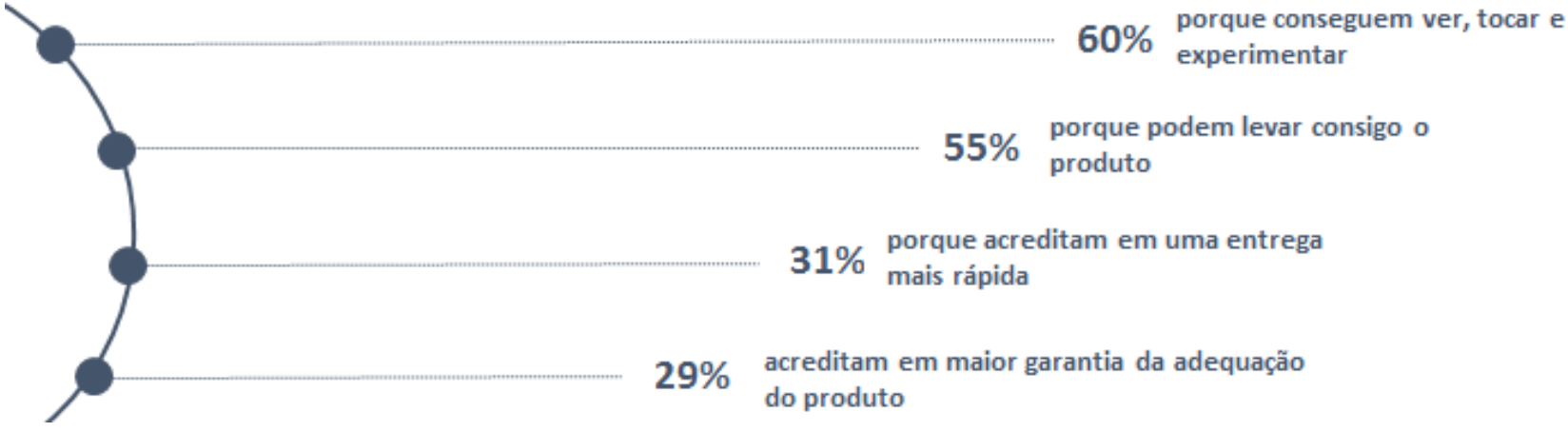

Figura 4: Razões de preferência do consumidor brasileiro por lojas físicas Fonte: pesquisa Global Total Retail PwC, 2015

Por fim, a pesquisa realizada pela PwC em 2015, também apresenta um vínculo entre o investimento do varejo brasileiro em redes sociais e como ele 
impacta na comunicação entre varejista e consumidor e no estímulo a sua motivação de compra.
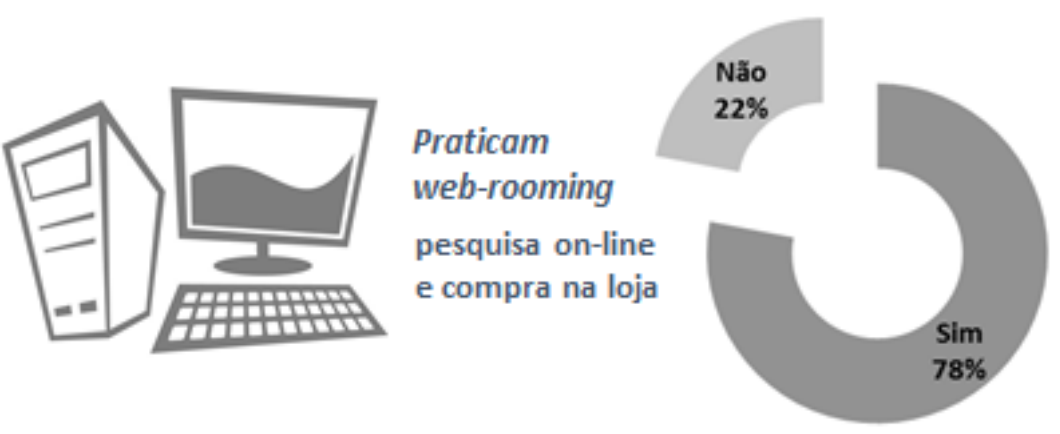

Figura 5: Prática de web-rooming pelo consumidor brasileiro Fonte: pesquisa Total Global Retail Pwc, 2015

De acordo com os resultados, o consumidor brasileiro vem utilizando as informações disponibilizadas pelos varejistas em redes sociais para auxiliar na sua atuação no processo decisório.

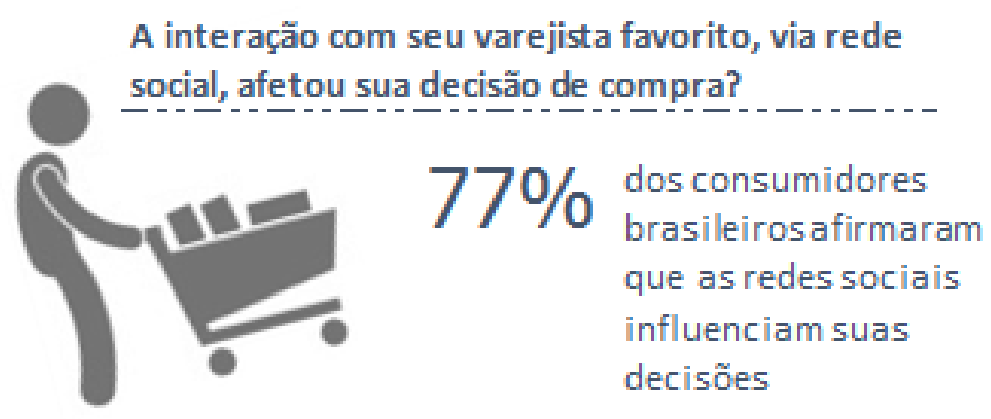

Figura 6: Relação com o varejista brasileiro via rede social Fonte: pesquisa Global Total Retail PwC, 2015 


\section{Metodologia de Pesquisa}

Para alcançar a proposta desse artigo, será aplicada uma pesquisa de marketing que, de acordo com Malhotra (2000), combina a análise e percepção objetiva das informações coletadas para auxiliar o embasamento da tomada de decisão relacionada a situações que requerem aplicação de marketing.

\subsection{Tipo de pesquisa utilizada}

Com o objetivo de realizar esse estudo, foi levantada uma amostra de dados para avaliação a partir de questionamentos elaborados com base no método survey. Esse método é apropriado para a obtenção de dados ou informações sobre as características, opiniões ou ações de grupos, representados por uma parcela da população alvo, utilizando um instrumento de pesquisa. (PINSONNEAUT; KRAEMER, 1993)

A survey é utilizada para obtenção de informações quanto à prevalência, distribuição e inter-relação de variáveis no âmbito de uma população. (Figueiredo, 2004, p. 114)

Segundo Fink (1995), a survey é ideal para produzir descrições quantitativas de uma população que respondam perguntas com foco de interesse bem definido (perguntas objetivas, como o quê, quais, quando e quanto). É adequada também, por considerar que o objeto de interesse é recorrente e ocorre no presente, como é o caso do tema discutido.

\subsection{Seleção dos informantes}

Uma survey deve ser respondida por elementos. Segundo Babbie (1999), elementos são a unidade sobre a qual a informação é coletada e que serve de base para a análise.

Foram considerados elegíveis como elementos para a coleta de dados desta pesquisa informantes que afirmaram consumir em papelarias, por 
compreender que apenas estes oferecem respostas pertinentes para a análise proposta.

Para compor a amostra foi utilizada uma seleção por disponibilidade da população de interesse, ou seja, segundo Bickman e Rog (1997) os participantes foram escolhidos por conveniência e de forma não probabilística.

Foram ignorados aspectos sazonais do comércio para a pesquisa e, portanto, os respondentes deveriam ser apenas maiores de 18 anos, sem limitação máxima de idade, por entender que, nessas condições, o público-alvo de uma papelaria não tem faixa etária pré-definida.

\subsection{Procedimentos e instrumentos de coleta de dados utilizados}

O procedimento de pesquisa survey utilizado neste artigo teve finalidade exploratória. De acordo com Pinsoneaut e Kraemer (1993), essa classificação busca identificar os conceitos sobre um tópico e dar ênfase na determinação de quais fatores devem ser medidos sobre ele, com base nas dimensões da população de interesse.

Segundo Babbie (1999) e Bryman (2001) há dois instrumentos de coleta de dados associados à pesquisa survey: o questionário administrado e a entrevista estruturada.

O instrumento utilizado foi o questionário e o método de aplicação foi feito pela internet, pela divulgação em redes sociais. Assim, o questionário foi disponibilizado no Facebook e no Whatsapp e ficou acessível por cerca de uma semana, obedecendo as características do modelo interseccional, ou seja, com a coleta de dados de uma população realizada em um único intervalo de tempo.

Sua elaboração ocorreu com o auxílio do software Survey Monkey, selecionado por possibilitar diferentes suportes à análise das respostas extraídas e um sistema simples de usabilidade para os respondentes. As perguntas foram respondidas individualmente e o preenchimento das questões levava cerca de quatro minutos.

Segundo as premissas de Gil (1991) para criação de um questionário concreto, a enquete incluiu questões somente relacionadas ao tema trabalhado, em sua maioria fechadas e com alternativas exaustivas e cada uma delas conta com instruções para o preenchimento correto.

Quanto à quantidade de respondentes, de forma geral, os surveys são utilizados para através das respostas de uma parcela da população, estuda-la como um todo. Para isso, deve-se calcular uma amostra que realmente 
represente a população. (BRYMAN, 1989). Sendo assim, a estimativa de respostas necessárias também foi realizada com ajuda do software Survey Monkey.

A população base considerou a quantidade de habitantes maiores de 18 anos no Rio de Janeiro (cerca de cinco milhões de pessoas em 2017, segundo o IBGE) e um grau de confiança de $90 \%$, resultando no tamanho da amostra calculado em 94 respondentes. De acordo com Fink (1995), o tamanho da amostra deve possuir o número necessário de respostas que gere informações precisas e confiáveis para a análise em questão.

\subsection{Processo de análise de dados}

Segundo Pereira (1999), a análise dos dados refere-se ao processamento de informações coletadas através do instrumento de pesquisa utilizado. No caso deste estudo, a análise de dados coletados por meio de um questionário.

Para Kotler (2000), a coleta estruturada de dados por meio de um questionário é comum na busca por resultados primários, como no caso do presente artigo. O questionário apresentado foi composto por 12 perguntas, organizadas de acordo com o roteiro desenvolvido a partir do tema proposto (presente no anexo I).

Estabelecidas essas definições, as respostas obtidas foram categorizadas de acordo com a natureza das perguntas realizadas. Sendo assim, cada pergunta considerou análises diferentes, utilizando-se os métodos descritivo e causal, acompanhando a relação das variáveis identificadas.

Ou seja, os métodos foram aplicados com o objetivo de mapear a distribuição de um fenômeno na população estudada e determinar a frequência com que algo ocorre ou a relação entre duas variáveis (atributo de influência e realização da compra, no caso), sendo tipicamente guiado por uma hipótese inicial e aplicando testes, para observar a relação causa e efeito destas variáveis. (CHURCHILL, 2000).

A partir destes métodos apresentados, o procedimento da análise de dados coletados, foi realizado pela combinação dos softwares Survey Monkey e Excel. A extração das informações do survey aplicado foi alocada em planilhas que possibilitaram categorizar os dados e as relações das variáveis entre eles observadas. 


\subsection{Limitações do estudo}

Conforme apresentado, o presente estudo é realizado com o objetivo de identificar os atributos que influenciam no processo decisório de compra dos consumidores do comércio varejista de papelarias do Rio de Janeiro. Esta análise contemplou dados coletados por meio de um questionário apresentado em redes sociais.

A combinação entre o instrumento selecionado, o método de aplicação de pesquisa utilizada e a amostra levantada resulta em dados extraídos com algumas limitações. Uma destas, segundo Gorman (2000) é assumir que todos os respondentes tem acesso à redes sociais, o que pode não constituir uma amostra realista da população.

As respostas adquiridas também devem considerar baixa confiabilidade, uma vez que muitos respondentes podem informar dados não verdadeiros que não são passíveis de verificação. (EVANS \& MATHUR, 2005).

Deve-se também considerar que amostras não probabilísticas generalizam os resultados obtidos, o que também é fonte de erro. De acordo com Couper (2000), uma clara distinção deve ser feita entre a pesquisa científica desenhada para permitir a generalização para a população e o esforço de coleta de dados que enfatiza somente o número de respondentes ao invés de sua representatividade. 


\section{Descrição e análise dos resultados}

As avaliações e observações feitas com base nesses resultados foram analisadas a partir das teorias apresentadas na revisão de leitura feita para este estudo. As respostas alcançadas fundamentaram as interpretações apresentadas a seguir nessa seção.

\subsection{Perfil dos participantes}

O questionário survey elaborado para realizar o levantamento de dados necessário para a presente pesquisa foi enviado, por meio das redes sociais selecionadas para cerca de 150 pessoas, alcançando uma taxa de respostas de $72 \%$, ou seja, composta por 108 respondentes.

Dentre estes, apenas 4\% afirmaram não frequentar papelarias de maneira geral e nenhum entrevistado informou optar pela compra de artigos de papelarias exclusivamente pela internet, sendo que só $1 \%$ disse consumir também on-line.

Compreende-se neste levantamento, por fim, 98 elementos que anunciaram frequentar papelarias da cidade do Rio de Janeiro, alcançando a amostra ideal estimada em 94 respondentes necessária para o estudo, que foi calculada no software Survey Monkey a partir dos princípios apresentados por Fink (1995). Analisando o grupo de pessoas elegíveis para este estudo, constata-se uma proporção formada $56 \%$ por mulheres e $80 \%$ por pessoas maiores de 22 anos.

É válido observar que a renda familiar mensal se apresentou em proporções equilibradas pelos respondentes e que apenas $44 \%$ dos entrevistados não apresentaram relação com pessoas matriculadas no colégio, que são consideradas parte importante do público alvo de papelarias.

\subsection{Conceito e funções de papelarias na visão do consumidor}

Para buscar conceber o significado de papelarias, primeiramente, é importante lembrar que estas podem fazem, em geral, parte do segmento de vendas do setor varejista. Ou seja, aplicados os conceitos de Kotler (2000), 
pode-se afirmar que são estabelecimentos de varejo que desempenham o papel de venda de artigos desse segmento, para atender a necessidade do consumidor final de mercadorias próprias de papelarias.

O conceito de papelarias foi, então, definido pelos entrevistados de acordo com o segmento de artigos oferecidos nos portfólios dos estabelecimentos em questão. Conforme apresentado, segundo o site do SEBRAE (2017), o modelo de negócios de papelarias evoluiu da oferta de itens tradicionais do setor, sendo hoje capaz de alcançar consumidores que busquem grande diversidade de produtos.

A partir da apresentação desse significado geral, os respondentes foram habilitados a opinar sobre suas considerações quanto à concepção final de mercadorias oferecidas por papelarias.

Dessa forma, pode-se compreender que a grande maioria dos entrevistados atribui à papelarias a oferta de material escolar e artigos de escritório (totalizando cada, $85 \%$ das respostas). Mais da metade das respostas também contempla a comercialização de produtos de pintura (55\%) e de itens de bazar, incluindo presentes (54\%).

Um grande número dos respondentes também entende por papelarias lojas que ofereçam soluções para o dia-a-dia e artigos básicos de informática representando, respectivamente, 48 e $47 \%$ das respostas obtidas. E, por fim, no campo de resposta livre, alguns entrevistados apontaram a oferta de serviços gráficos, incluindo impressão digital, cópias e digitalização de documentos, como elementos, geralmente, também oferecidos por papelarias.

A partir dos dados obtidos, é correto afirmar que apenas $38 \%$ dos entrevistados entendem por papelarias estabelecimentos que oferecem unicamente material escolar e de escritório. E, cerca de metade de todos os respondentes acreditam que o varejo de papelarias envolve a venda de todas as alternativas apresentadas, aqui relacionadas: material escolar e de escritório, produtos de pintura, itens de bazar e presentes, soluções para o dia-a-dia e artigos básicos de informática.

Segundo é apresentado por Las Casas e Garcia (2007), existem treze categorias de varejo e a classificação destes, como papelarias, vai depender dos quantidade de segmentos de produtos ofertados e/ou do tamanho de varejo praticado. Assim, ainda de acordo com os autores, em um primeiro momento, entende-se por papelarias estabelecimentos classificados, dentre essas categorias, como lojas especializadas, oferecendo apenas sua linha específica de produtos em quantidades limitadas. 
Quando o varejo é identificado como um pequeno negócio e a gerência mantém um contato mais direto com os clientes, porém, as papelarias podem assumir o caráter de lojas independentes. E, atualmente, algumas papelarias podem se encaixar também no perfil de loja de variedades, com extensa linha de mercadorias, geralmente oferecidas por um baixo valor. (LAS CASAS; GARCIA, 2007).

A partir da compreensão atribuída ao conceito de varejo pelos entrevistados, busca-se entender a aplicação das funções básicas do varejo, apresentadas por Las Casas (2004) quando referente ao segmento de papelarias, relacionando-as às diferentes categorias.

A primeira função apresentada pelo autor é a obtenção de mercadorias por meio de compras e tem relação com o portfólio oferecido pelo varejista. Quando as papelarias fornecem apenas material escolar e de escritório (como entendido por $38 \%$ dos respondentes) podem ser compreendidas como lojas especializadas ou independentes e dependerão das definições das próximas funções para uma classificação final mais assertiva.

Sendo assim, formação de preços ainda não é capaz de definir uma classificação específica, porém, quando a venda pessoal possui um caráter mais próximo do consumidor, com facilidade de acesso aos gerentes e/ou proprietários, tratam-se de lojas independentes. Por outro lado, a oferta de serviços que valorizem a venda é utilizada pelas lojas especializadas.

Da mesma forma, $50 \%$ dos entrevistados entendem que papelarias podem oferecer todos os segmentos de produtos apresentados e, nesse caso, podem ser categorizadas em lojas independentes ou de variedade. Diante disso, a prática de preços baixos é suficiente para identificá-la como uma loja de variedade. No entanto, a prática de vendas mais próxima do consumidor também define lojas independentes nessa situação.

\subsection{Motivações para consumo}

Conforme foi apresentado, segundo Solomon (2016), as situações que envolvem a atuação do cliente antes, durante e depois da compra fazem parte do processo de consumo. A partir da principal definição de marketing que foi apresentada, é correto afirmar que as empresas existem, fundamentalmente para satisfazer as necessidades das pessoas. (KOTLER, 2000; SOLOMON, 2016). 
Os autores Blackwell et. AL (2008) afirmam que o conhecimento das razões que justificam o consumo é importante para que a empresa atinja como resultado a obtenção de seus produtos por parte do consumidor.

Diversas razões levam à busca por papelarias, antes mesmo de realizar a compra de algum produto. De acordo com os respondentes, os principais motivos para visitar uma papelaria são representados pela proporção a seguir.

\begin{tabular}{|l|r|}
\hline \multicolumn{2}{|c|}{ Situações que levam à papelarias } \\
\hline Quando se procura por: & Relação \\
\hline Artigos próprios de papelarias & $93 \%$ \\
\hline Material Escolar & $54 \%$ \\
\hline Itens expostos na vitrine & $36 \%$ \\
\hline Presentes para datas comemorativas/feriados & $26 \%$ \\
\hline Variedade de mercadorias & $24 \%$ \\
\hline Presentes sem motivo específico & $21 \%$ \\
\hline Artigos para consumo próprio em datas comemorativas/feriados & $14 \%$ \\
\hline Produtos divulgados em propaganda & $14 \%$ \\
\hline Material administrativo da empresa & $11 \%$ \\
\hline
\end{tabular}

Figura 7: Motivos para visitar uma papelaria

Segundo Solomon (2016), o primeiro estágio do processo decisório de compra diz respeito ao reconhecimento do problema e, tendo isso em mente, a análise dos dados aponta que, para sanar os problemas de seus consumidores, as papelarias devem, primariamente, oferecer artigos próprios de seu segmento. Por essa definição, compreende-se os itens identificados anteriormente no conceito de papelarias.

Ou seja, apesar de se esperar que esses artigos façam já parte do portfólio das papelarias, avalia-se a importância de manter um estoque completo, visto que, possivelmente, causaria frustração em um cliente visitar uma papelaria e não encontra-los.

Como observado, dentre os respondentes, apenas $44 \%$ afirmaram possuir em seu perfil, relacionamentos com pessoas matriculadas em colégios, porém, pode-se perceber que o número aumenta para $54 \%$ que assumiram consumir itens de material escolar. Conclui-se que, apesar da tendência de compra de material escolar por obrigações para com o colégio, muitas pessoas necessitam ou se interessam por esses produtos no dia-a-dia.

Podemos afirmar, então, a partir das literaturas apresentadas que as duas principais razões para compras em papelarias são utilitárias. É válido, porém, 
apontar que uma delas (compra de material escolar) pode assumir, em grande parte, caráter sazonal, sendo necessária sua realização em determinados períodos do ano.

Com base nas principais motivações listadas, observa-se que, quase metade dos entrevistados (cerca de 47\%) informaram frequentar papelarias na busca por presentear alguém. Sendo que parte destes realizam essa busca em épocas comemorativas (aniversários e feriados, por exemplo) e outros assumiram procurar por presentes sem necessidade de um motivo especial.

Os respondentes que se apresentaram motivados a frequentar uma papelaria na busca por presentes em datas comemorativas são guiados, em geral, também por aspectos utilitários. Entretanto, essa compra não necessariamente precisa ser realizada em um estabelecimento de papelaria, os motivos para escolher esse tipo de loja, se relacionados com as outras respostas oferecidas, podem ser considerados hedônicos também nesse caso. (HUI e BATESON, 1991).

Como foi exposto por Mattar (2011), uma das tarefas do varejo, considerando este como a última etapa do processo de distribuição, é agregar valor aos produtos e serviços oferecidos. Sendo assim e considerando que $40 \%$ dos entrevistados informaram frequentar papelarias para presentes ou consumo próprio em datas comemorativas é seguro afirmar que, os estabelecimentos de varejo devem preparar seu portfólio de mercadorias e serviços de maneira específica para a natureza de cada data especial, buscando agregar valor na experiência do cliente considerando esses aspectos sazonais.

O consumidor em geral, mas principalmente o de varejo está sujeito à sensações decorrentes de estímulos liberados no ambiente. (SOLOMON, 2016). Dentre essas sensações, pode-se perceber relações com o tato, visão e olfato, influenciando na percepção dos indivíduos expostos a elas.

A presente análise corrobora essa teoria, especialmente ao apresentar um número significativo de entrevistados (36 das 98 respostas consideradas) instigados a adentrar em uma papelaria devido à apresentação de sua vitrine. Considera-se assim que a necessidade do consumidor é encontrar o que foi exposto nela.

Essa motivação é claramente hedônica, segundo conceitos de Solomon (2016), pois o cliente em potencial assume uma experiência prazerosa e se sente mais disposto a comprar por conta da forma como estes produtos são expostos. Situações que não foram predispostas nas questões disponibilizadas também foram apontadas por alguns respondentes e dizem respeito, 
principalmente, ao visual das papelarias. Alguns entrevistados afirmaram que se atraem pelo ambiente e exposição dos itens dentro da loja. Outros evidenciaram entrar em papelarias sem nenhuma razão específica.

"Ás vezes entro só por entrar, para passear e bater perna dentro da loja. Acabo comprando sem nem precisar, simplesmente por gostar de itens de papelaria."

(respondente no 12).

Outras situações também apresentaram quantidades consideráveis de respondentes motivados a frequentar uma papelaria por elas, como: procura por variedade de mercadorias, por produtos divulgados em propagandas e por materiais administrativos para a empresa em que trabalha. Entretanto, os números não são tão significativos quando comparados com o todo analisado.

\subsection{Atributos percebidos}

De acordo com a apresentação do processo decisório de compra realizado na revisão de leitura, são constatados cinco estágios os quais as pessoas atravessam durante o consumo. As motivações para frequentar uma papelaria, reconhecidas no capítulo anterior compõe basicamente a primeira fase deste processo, ou seja, o reconhecimento do problema, manifestado em forma de razões para dirigir-se a uma papelaria.

Estabelecido o conceito de papelarias sob a ótica dos consumidores e as principais motivações que o levam a visita-las, a identificação de quais os atributos mais relevantes no processo decisório de compra para esses indivíduos quando aplicado ao consumo no varejo de papelarias se torna mais viável.

Uma das importâncias de se definir os fatores mais influentes sobre 0 processo de compra de qualquer segmento de vendas é propor ações sobre o comportamento desse consumidor capazes de induzi-lo a realizar uma compra. Obedecendo a citação de Drucker (1973), ao compreender o cliente e seu comportamento, os produtos e serviços se vendem com mais facilidade.

Os atributos importantes para o consumidor podem representar apenas uma fração da compreensão do seu comportamento, porém já podem ser considerados suficientes para iniciar debates sobre suas tendências durante a passagem pelo processo de compra. Eles podem ser utilizados de modo a 
impactar os próximos dois passos do processo de compra: busca de informações e avaliação de alternativas.

\subsubsection{Identificação}

Primeiramente, ao perceber uma necessidade que pode ser sanada pela visita a uma papelaria e a possível compra realizada nela, o consumidor deve procurar informações sobre os estabelecimentos que forneçam essa solução.

Esses estabelecimentos podem ser apresentados em várias categorias de tamanho. Para o propósito desta pesquisa, foram consideradas apenas duas: grande ou pequeno varejo. A análise, posteriormente, traz a preferência em relação a localização comercial e, por fim, buscou identificar a relação entre as motivações de consumo e o tipo de varejo e localização comercial selecionados como favoritos.

\begin{tabular}{|l|c|}
\hline \multicolumn{2}{|c|}{ Relação } \\
\hline \multicolumn{1}{|c|}{ Tamanho } & Taxa de Preferência \\
\hline Pequeno & $63 \%$ \\
\hline Grande & $37 \%$ \\
\hline
\end{tabular}

Figura 8: Relação entre o tamanho do varejo e a preferência do consumidor

O vínculo entre a escolha por um grande varejo de papelarias e motivações utilitárias de compra também pode ser percebido. Dentre os entrevistados, $75 \%$ dos que apresentaram preferência pelo grande varejo também afirmaram frequentar papelarias na busca por material escolar no início do ano letivo.

\begin{tabular}{|c|c|c|c|}
\hline \multicolumn{2}{|l|}{ Relação } & \multirow[b]{2}{*}{ Grande Varejo } & \multirow[b]{2}{*}{ Pequeno Varejo } \\
\hline Tipo de Comércio e Localização & Preferência & & \\
\hline Shopping & $24 \%$ & $13 \%$ & $11 \%$ \\
\hline Comércio de rua & $27 \%$ & $2 \%$ & $25 \%$ \\
\hline O mais próximo, independente de tipo & $12 \%$ & $8 \%$ & $4 \%$ \\
\hline Local com maior variedade & $20 \%$ & & \\
\hline O mais próximo, independente de tamanho e tipo & $11 \%$ & & \\
\hline Local de marca conhecida & $5 \%$ & & \\
\hline
\end{tabular}

Figura 9: Relação tipo de varejo x tamanho do varejo x preferência do consumidor 
Referente ao tipo de comércio então, pode-se notar uma leve predileção por papelarias localizadas em lojas de rua e dentre elas, a grande maioria opta pelo pequeno varejista. Nesse caso, outro tipo de razão utilitária mostrou-se relevante, $50 \%$ destas pessoas que afirmaram preferir essa combinação de localização e tipo de varejo, são motivadas pela compra de itens específicos de papelarias.

A inclinação por selecionar frequentar papelarias que se encontram em um shopping atinge uma parcela muito parecida da população, porém, nesse caso, não é possível perceber uma preferência clara entre o tamanho de varejo oferecido.

Por outro lado, foi observado que as pessoas que preferem lojas de pequeno varejo em shoppings, são formadas, em $40 \%$ pelos respondentes que se mostraram dispostos a frequentar papelarias por conta da exposição da vitrine, ou seja, por motivações hedônicas.

É possível constatar também que um grande número de pessoas opta por lojas que ofereçam, geralmente, uma maior variedade de produtos em seu portfólio, também sem depender do tamanho e do tipo.

Pode-se reparar que um número menos significativo de respondentes assumiu escolher o estabelecimento apenas pela proximidade, livre de favoritismo pela localização comercial e pelo tamanho, assim como indivíduos que selecionam uma papelaria pela marca atribuída a ela.

Dito isso, considera-se aqui estabelecido o segundo passo do processo decisório de compra (busca de informação), determinando as melhores alternativas para procurar por papelarias sob a visão do consumidor. Esse consumidor é encaminhado, portanto, para a terceira fase do processo decisório, avaliando as possíveis escolhas para atendimento de sua necessidade.

Segundo Mowen e Minor (2003), é nesta etapa que os atributos são constatados pelos clientes e, enfim, motivam o processo de consumo nos estabelecimentos. Em papelarias, não é diferente, porém, a pesquisa busca analisar os atributos percebidos pela maioria dos consumidores, especialmente, ao se visitar esse segmento de lojas.

A proporção apresentada na figura 10 aponta quais aspectos se mostraram relevantes em relação à quantidade de consumidores, ou seja, foram escolhidos por determinada quantidade de entrevistados como importantes.

Com o objetivo de associar os atributos relevantes para a maioria dos respondentes, os entrevistados, nesse caso, poderiam selecionar mais de um atributo considerado importante em seu processo de consumo em papelarias. $\mathrm{O}$ 
total de votos computados para todos os atributos foi de 418 e é em cima deste número que a proporção acima foi calculada.

\begin{tabular}{|l|c|}
\hline \multicolumn{2}{|c|}{ Quando vai à uma papelaria, o que considera importante? } \\
\hline Preço & $\begin{array}{c}\text { Quantidade de } \\
\text { escolhas/Total de votos }\end{array}$ \\
\hline Variedade & $20 \%$ \\
\hline Bom atendimento & $19 \%$ \\
\hline Localização & $17 \%$ \\
\hline Facilidade de acesso & $13 \%$ \\
\hline Conhecimento dos vendedores & $10 \%$ \\
\hline Tempo gasto & $7 \%$ \\
\hline Ambiente & $6 \%$ \\
\hline Personalização dos serviços & $6 \%$ \\
\hline \multicolumn{2}{l|}{} \\
\cline { 2 - 2 }
\end{tabular}

Figura 10: Atributos para a maioria dos consumidores de papelaria

O atributo preço foi o escolhido pela maioria dos respondentes, dentre todos os apresentados. É válido apontar que a quantidade de entrevistados que afirmou ser influenciada por esse atributo é muito similar ao total de pessoas que selecionaram também variedade e bom atendimento.

É importante mencionar que todas as opções fornecidas foram escolhidas como resposta por pelo menos 12 pessoas, dentre os 98 respondentes e representam no mínimo 3\% dos votos computados.

Sendo assim, os aspectos nomeados como: tempo gasto na compra, ambiente apresentado pela loja e personalização dos serviços oferecidos, aparecem como atributos importantes para poucas pessoas, com base no comparativo sobre o levantamento feito.

\subsubsection{Grau de importância}

Uma vez identificados quais os principais atributos capazes de motivar o comportamento do consumidor de papelarias nas etapas de busca por informações e avaliação de alternativas do processo decisório de compra, o estudo procurou analisa-los a partir da atribuição de um grau de importância para cada um deles. 
Dessa forma, é possível compreender não só o fator relevância, mas a medição e ordenação da relevância de um atributo em comparação com os demais. A partir dos nove atributos já apresentados, os respondentes foram habilitados a atribuir notas de acordo com o grau de importância que eles representam.

A nota um foi associada ao aspecto considerado como mais essencial, enquanto a nota nove, relacionada ao aspecto menos relevante. Segue o resultado das médias das notas fornecidas pelos entrevistados para cada atributo na figura abaixo:

\begin{tabular}{|l|c|}
\hline \multicolumn{2}{|c|}{ Hierarquização dos Atributos } \\
\hline \multicolumn{1}{|c|}{ Atributos } & $\begin{array}{c}\text { Médlia das notas } \\
\text { atribuídas nas respostas }\end{array}$ \\
\hline Bom atendimento & 4.0 \\
\hline Variedade & 4.4 \\
\hline Preço & 4.8 \\
\hline Tempo gasto & 5.2 \\
\hline Conhecimento dos vendedores & 5.2 \\
\hline Ambiente & 5.3 \\
\hline Localização & 5.3 \\
\hline Facilidade de acesso & 5.3 \\
\hline Personalização dos serviços & 5.4 \\
\hline \multicolumn{1}{|c|}{ Média } & 5.0 \\
\hline
\end{tabular}

Figura 11: Hierarquização dos atributos identificados pelos consumidores

Pode-se notar, portanto, que preço, variedade e bom atendimento foram, respectivamente, os aspectos escolhidos pela maioria dos respondentes como importantes em papelarias e também tiveram as melhores notas atribuídas em relação ao grau de relevância.

Deve-se observar que o atributo preço, escolhido por quase $100 \%$ dos respondentes como importante para definição de sua preferência por uma papelaria ante a outra, quando comparado aos demais, não é selecionado como mais importante hierarquicamente.

O bom atendimento é o primeiro item que o consumidor avalia para determinar qual papelaria se destaca mais em sua opinião, seguido pela variedade de produtos oferecida no estabelecimento para que, finalmente, 
analise o preço aplicado como justo. Os próximos seis atributos obtiveram pontuações equilibradas, expondo opiniões divididas nesse caso.

Com base nos dados do questionário, pode-se afirmar que bom atendimento, preço e variedade são relevantes para todas as classes sociais que consomem em papelarias.

O conhecimento dos vendedores sobre os produtos ofertados, bem como o tempo gasto na realização do processo de compra receberam avaliações mais positivas de clientes com rendas acima de seis salários mínimos ( $R \$ 5.622,00)$.

Localização e facilidade de acesso apresentaram maior importância para consumidores de rendas abaixo dessa faixa. O aspecto personalização dos serviços ofertados atingiu os respondentes, em relação a sua renda, de maneira equilibrada.

A pesquisa aponta também que 0 ambiente apresentado pelo estabelecimento recebeu notas melhores quando avaliado por pessoas do gênero feminino, assim como o aspecto conhecimento dos vendedores foi rateado como superior pelo público masculino. 


\section{Conclusão}

A identificação dos atributos de maior relevância no varejo, sob a ótica dos consumidores de papelarias era a meta primária do presente estudo. Os resultados apresentados buscaram definir, também, quais motivações e situações que levam à percepção dos atributos de relevância neste setor e qual a hierarquização destes, medida com base em seu grau de importância.

Em paralelo, a pesquisa propôs avaliar a melhor localização comercial para estabelecimentos que praticam essa atividade, por meio de lojas físicas. Análises a partir das circunstâncias tecnológicas apresentadas nos dias de hoje e os impactos causados sobre ess a parcela do comércio.

A partir da revisão de teorias sobre o mercado varejista e contextualização brasileira, de acordo com alguns autores, principalmente Mattar (2011). Literaturas de consumo em geral, comportamento dos consumidores e das etapas que compõe o processo decisório de compra, foram apresentadas segundo a ótica de outros, como: Kotler (2000) e Solomon (2016).

Além de dados secundários sobre o setor de varejo e comércio colhidos em pesquisas realizadas pela PricewaterhouseCoopers, a avaliação contou com dados primários obtidos a partir de respostas dos consumidores a um questionário elaborado pelo método survey, estudado fundamentalmente por meio da obra de Fink (1995).

Com base nas informações coletadas, pode-se considerar a meta do estudo como alcançada, ou seja, os atributos relevantes para consumidores de papelarias foram identificados com sucesso. Conclui-se, portanto, que bom atendimento, variedade de produtos e preço práticos são os aspectos que mais impactam na forma com que o consumidor se comporta no processo decisório de compras em papelarias.

Sendo que, compreende-se por papelarias, na visão destes consumidores, principalmente lojas que vão além da oferta tradicional e apresentam um portfólio completo de artigos de escritório, informática e presentes também. As motivações dos clientes para visitarem papelarias, em primeiro lugar, vão além da busca por mercadorias dessa natureza, como por influência da exposição da vitrine, por exemplo. 
A partir dessas informações, conclui-se também que cada motivação de compra identificada para os consumidores de papelaria sujeita a sofrer influência em diferentes graus de cada atributo. Ou seja, pessoas que buscam comprar material escolar, por exemplo, apresentaram maior propensão a optar por papelarias em forma de grandes varejistas.

Papelarias não apresentam um público específico em relação à renda e nem são representadas por apenas um tipo ou tamanho de comércio. Esses estabelecimentos agradam consumidores que gostam de ir ao shopping, bem como aos que preferem lojas de rua.

Pode-se supor a partir destes resultados, que os consumidores de papelarias são muito ligados aos aspectos visuais que lojas desse setor podem ostentar, quando relacionados às suas motivações para compras. Por outro lado, atributos dessa categoria não representam tanta relevância na hora do processo de consumo.

Outro fator é a percepção de que esse segmento é realmente afetado pela sazonalidade, mas exibe potencial para alcançar clientes durante todo o ano devido à variedade que pode oferecer.

\subsection{Sugestões e recomendações para novos estudos}

Assim que apresentadas as respostas para esse estudo, é possível utilizar a identificação dos atributos mais importantes e a hierarquização destes para melhorar o serviço oferecido no comércio de papelarias, no Rio de Janeiro.

Detectados estes atributos, estudos futuros poderiam procurar apresentar as formas com que estes atributos impactam o comportamento do consumidor de papelarias.

Propõe-se aqui utilizando os atributos reconhecidos neste estudo como mais importantes, a realização de um trabalho a partir dos artigos oferecidos no conceito de papelarias exposto pelos consumidores. Medir, de acordo com estes atributos o impacto específico sobre cada linha de mercadoria.

Um exemplo deste seria uma pesquisa capaz de preencher uma tabela no modelo de Fishbein (como o apresentado na figura 12). Dessa forma, o respondente poderia atribuir o grau de importância especificamente a cada linha de produtos oferecidos identificada e perceber que em relação a itens de pintura, por exemplo, o consumidor se importa mais com o conhecimento dos vendedores sobre a mercadoria. 


\begin{tabular}{|c|c|c|c|c|c|c|}
\hline & \multicolumn{6}{|c|}{$\begin{array}{c}\text { Modelo Fishbein } \\
\text { de Papelarias }\end{array}$} \\
\hline & Preço & Variedade & Atendimento & Localização & Acesso & $\begin{array}{l}\text { Conhecimento } \\
\text { dos Vendedores }\end{array}$ \\
\hline $\begin{array}{r}\text { Material } \\
\text { Escolar }\end{array}$ & & & & & & \\
\hline $\begin{array}{r}\text { Artigos } \\
\text { de Escritório }\end{array}$ & & & & & & \\
\hline $\begin{array}{r}\text { Produtos } \\
\text { de Pintura }\end{array}$ & & & & & & \\
\hline $\begin{array}{r}\text { Itens de Bazar e } \\
\text { Presentes }\end{array}$ & & & & & & \\
\hline
\end{tabular}

Figura 12: Proposta exemplo de modelo de Fishbein para estudos futuros

Além disso, preocupar-se com a globalização que se vem alcançando, seria de interesse também para o prosseguimento de estudos que apliquem o setor de papelarias no e-commerce e os desdobramentos de suas consequências.

Por fim, recomenda-se que seja realizado um estudo sobre aspectos importantes para outros setores do comércio carioca, para que se possa observar quais aspectos são de fato importantes para papelaria e não para o comércio varejista como um todo. 


\section{Referências Bibliográficas}

AAKER, D. Building strong brands. London: Free Press, 1996.

BABBIE, E. Métodos de Pesquisas de Survey. Belo Horizonte: Ed. UFMG, 2001

BAKER, J.; WAKEFIELD, K. L. How consumer shopping orientation influences perceived crowding, excitement, and stress a the mal. Journal of the Academy of Marketing Science, v. 40, n. 6, p. 791-806, 2012.

BARROS, A. J. S.; LEHFELD, N. A. S. Fundamentos de Metodologia Científica. 3.ed. São Paulo: Prentice Hall, 2007

BERRY, L. Retail Businesses Are Service Businesses. Journal of Retailing, v. 62, n. 1, p. 3-6, 1986.

BICKMAN, L.; ROG, D. J. (Eds.) Handbook of applied social research methods. Thousand Oaks: SAGE Publications, 1997

BRYMAN, A. Social Research Methods. Oxford, Oxford University Press, 2001.

CHURCHILL, G. A. e PETER J. P. Marketing: Criando Valor para o Cliente, 2000, São Paulo, Saraiva, $2^{\circ}$ ed.

Comércio fechou 108,7 mil lojas no ano passado. Estadão, São Paulo, 13 fev. 2017. Disponível em: <http://economia.estadao.com.br/noticias/geral,comerciofechou-108-7-mil-lojas-e-cortou-182-mil-vagas-no-ano-passado,70001663111>. Acesso em: 20 de julho de 2017.

Comércio do Rio vendeu menos $8,5 \%$ no primeiro trimestre. G1, Rio de Janeiro, 26 abr. 2017. Disponível em: < http://g1.globo.com/rio-dejaneiro/noticia/comercio-do-rio-vendeu-menos-85-a-menos-no-primeiro-trimestrediz-cdl.ghtml>. Acesso em: 18 de setembro de 2017.

Deloitte Touche Tohmatsu Limited. Consumer Survey. Rio de Janeiro, 2008 Disponível em: < http://www2.deloitte.com/>. Acesso em: 25 de Outubro. 2017.

Deloitte. PODEROSOS do Varejo Global. 2015. Disponível em:

https://www2.deloitte.com/br/pt/pages/consumer.../poderosos-do-varejoglobal.html>. Acesso em: 19 out. 2017.

DRUCKER, P. Management: tasks, responsibilities, practices. Nova York: Harper and Row, 1973.

ENGEL, J. F.; BLACKWELL, R. D.; MINIARD, P. W. Comportamento do consumidor. $8^{a}$ edição. Rio de Janeiro: Livros Técnicos e Científicos, 2000. 
ENGEL, J. F. Comportamento do consumidor. 9a edição, São Paulo: Pioneira Thompson Learning, 2005.

ELLIOT, R. and WATTANASUWAN, K. Brands as symbolic resources for the construction of identity. International Journal of Advertising, v.17, n.2, p 131 144, 1998.

FECOMERCIO - FECOMÉRCIO RJ, Ipsos. Consumo material escolar. 2015. Disponível em: <http://www.fecomercio-rj.org.br>. Acesso em: 28 set. 2017.

FIGUEIREDO, A. C. A construção do caso clínico: uma contribuição da psicanálise à psicopatologia e à saúde mental. Revista Latinoamericana de Psicopatologia Fundamental, v. 7, p 75-86, 2004.

FINK, A. The Survey Handbook. 2ª edição, Sage: Thousand Oaks, 1995.

FURTADO, W.; FRANCO, A. A. Decisão de compra: fatores iguais, pesos diferentes; Visão do consumidor sobre as pequenas e grandes redes de farmárcia. Revista de Gestão, Finanças e Contabilidade, UNEB, Salvador, v.1, n.1, p. 35-47, jan./dez., 2011.

GERTNER, D.; DIAZ, A. N. Marketing na internet e comportamento do consumidor: investigando a dicotomia hedonismo vs. utilitarismo. Revista de Administração Contemporânea - RAC, São Paulo, n. 3, p. 131-156, 1999.

GIL, A. C. Como elaborar projetos de pesquisa, São Paulo, Atlas. 3ª Ed. 1991.

HOLBROOK, M. B.; HIRSCHMAN, E. C. The experiential aspects of consumption: Consumer fantasies, feelings, and fun. Journal of Consumer Research, p.132-140,1982.

HUI, M. K.; BATESON, J. E. G. Perceived control and the effects of crowding and consumer choice on the service experience. Journal of Consumer Research, p. 174-184, 1991.

Instituto Brasileiro de Geografia e Estatística. Pesquisa Mensal do Comércio. Rio de Janeiro, 2017. Disponível em: < http://www.ibge.com.br/>. Acesso em: 25 de Setembro. 2017.

Instituto Brasileiro de Geografia e Estatística. Rio de Janeiro - Evolução Populacional e Pirâmide Etária. Rio de Janeiro, 2017 Disponível em: < http://www.ibge.com.br/>. Acesso em: 25 de Outubro. 2017.

Instituto para Desenvolvimento do Varejo. Varejo brasileiro - gráficos e arquivos. Rio de Janeiro, 2016 Disponível em: < http://www.idv.org.br/>. Acesso em: 25 de Outubro. 2017.

KAPFERER, J. N. Strategic brand management: creating and sustaining brand equity long term. London: Kogan Page, 1997.

KOTLER, P. Administração de Marketing: a edição do novo milênio. São Paulo: Prentice Hall, 2000.

KOTLER, P. e ARMStRONG, G. Princípios de Marketing, São Paulo, Prentice Hall. $12^{\mathrm{a}}$ Ed. 2010. 
KOTLER, P.; KELLER, K. L. Administração de Marketing, São Paulo: Pearson Education do Brasil. 14ª Ed. 2012.

KOTLER, P. Marketing para o Século XXI: como criar, conquistar e dominar mercados. São Paulo, Futura. 2009.

LAS CASAS, A. L., Marketing: conceitos, exercícios e casos. 6. Ed. São Paulo, Atlas. 2004.

LAS CASAS, A. L., Marketing de Varejo. 4. Ed. São Paulo, Pearson Prentice Hall. 2006.

LAS CASAS, A. L.; GARCIA, M. T. Estratégias de Marketing para Varejo: Inovações e diferenciações estratégicas que fazem a diferença no marketing de varejo. São Paulo, Novatec Editora. 2007.

MASLOW, A. H. Motivation and Personality. 2ª . ed. New York: Harper \& Row, 1970

MOWEN, J. C.; MINOR, M. S. Comportamento do consumidor. São Paulo: Prentice Hall, 2003.

OLIVEIRA, D. P. R. Planejamento Estratégicos-Conceitos Metodologia e Práticas. São Paulo. Atlas, 1999.

PECORARO, M.; UUSITALO, O. Exploring the everyday retail experience: The discourses of style and design. Journal of Consumer Behaviour, v. 13, n. 6, p. 429-441, 2014.

PricewaterhouseCoopers. O varejo e a era da disrupção, pesquisa Total Retail 2015 - pesquisa anual da PwC com os consumidores. Rio de Janeiro, 2015 Disponível em: < http://www.pwc.com.br/>. Acesso em: 25 de Outubro. 2017.

PricewaterhouseCoopers. O setor de varejo e o consumo no Brasil - Como enfrentar a crise. Rio de Janeiro, 2016 Disponível em: < http://www.pwc.com.br/>. Acesso em: 20 de Outubro. 2017.

PricewaterhouseCoopers. O novo sentido do sucesso para varejo e consumo. Rio de Janeiro, 2016 Disponível em: < http://www.pwc.com.br/>. Acesso em: 20 de Outubro. 2017.

PricewaterhouseCoopers. Alternativas de investimento num mercado cada vez mais competitivo, pesquisa Total Retail 2017 - pesquisa anual da PwC com os consumidores. Rio de Janeiro, 2017 Disponível em: < http://www.pwc.com.br/>. Acesso em: 25 de Outubro. 2017.

Revista da Papelaria. Impacto Visual nas Vendas. Rio de Janeiro, 2016 Disponível em: < http://www.revistadapapelaria.com.br/>. Acesso em: 25 de Outubro. 2017.

RICHERS, R. O enigmático mais indispensável consumidor: teoria e prática. Revista de Administração, v. 19 jul./set. de 1984, p. 46-56. 
ROCHA MALHOTRA, N. K., Pesquisa de Marketing: Uma orientação. 6. Ed. São Paulo, Bookman. 2011.

ROChA MALHOTRA, N. K., Pesquisa de Marketing: Foco na Decisão. 3. Ed. São Paulo, Pearson Prentice Hall. 2011.

SANTOS, E. e SILVA, D.; Comportamento do Consumidor da Comunidade de Marca Harley-Davidson e a Influência do Self-expandido. Revista Brasileira de Marketing - ReMark, Vol. 16, N. 1. Janeiro/Março. 2017

SCHIFFMAN, L. G.; KANUK, L. L. Comportamento do consumidor. 6ª edição. Rio de Janeiro: LTC, 2000.

SEBRAE - SEBRAE, Brasil. Como montar uma papelaria: Ideias de negócio. 2017. Disponível em:

<https://www.sebrae.com.br/sites/PortalSebrae/ideias/como-montar-umapapelaria,f3987a51b9105410VgnVCM1000003b74010aRCRD>. Acesso em: 02 nov. 2017.

SERRENTINO, A. O Presente e o Futuro do Varejo, São Paulo, Gouvea de Souza. $11^{\text {a }}$ Ed. 2007.

SHETH, N. J.; MITTAL, B.; NEWMAN, I. B. Comportamento do cliente: indo além do comportamento do consumidor. São Paulo: Atlas, 2001.

Sociedade Brasileira de Varejo e Consumo. O papel do varejo na economia brasileira. Rio de Janeiro, 2015 Disponível em: < http://www.sbvc.com.br/>. Acesso em: 25 de Outubro. 2017

SOLOMON, M. R., O Comportamento do Consumidor, Porto Alegre, Bookman. 11를. 2016.

Varejo brasileiro recua 6,2\% em 2016, e tem pior resultado desde 2001. Folha de S. Paulo, São Paulo, 14 fev. 2017. Disponível em:

<http://www1.folha.uol.com.br/mercado/2017/02/1858574-varejo-brasileiro-recua62-em-2016-pior-resultado-desde-2011.shtml>. Acesso em: 28 de junho de 2017.

Vendas no Varejo caem 4,5\% em 2016, mas e-commerce cresce 7,1\%. A Tribuna, Rio de Janeiro, 01 fev. 2017. Disponível em:

<http://www.atribuna.com.br/noticias/noticias-detalhe/economia/vendas-novarejo-caem-45-em-2016-mas-e-commerce-cresce-

71/?cHash=19826ada8fe0b7b6765dd2ed33b73b1a>. Acesso em: 25 de julho de 2017. 


\section{Apêndice I}

Comportamento do Consumidor de Papelarias do Rio de Janeiro

Esse questionário foi feito com o objetivo de gerar um levantamento para ser utilizado em um trabalho de conclusão de curso de graduação em Administração de Empresas da PUC-Rio e é de caráter anônimo.

1. Você frequenta papelarias (lojas físicas)?

_ Sim, constantemente.

_Sim, raramente.

_ Sim, mas apenas quando tenho necessidade.

__ Sim, mas prefiro comprar pela internet.

_ Sim, mas também compro pela internet.

_ Não, compro apenas pela internet.

_ Não, nunca vou a papelarias.

2. As papelarias que você frequenta são no estado do Rio de Janeiro?

- Sim

- Não

3. Qual é o seu gênero?

_ Masculino

_ Feminino

- Outros

4. Qual a sua idade?

_ Menor de 18 anos

_ Entre 18 e 21

_ De 21 a 29 
_ De 29 a 39

_ De 39 a 49

_ De 49 a 59

_ Maior de 59 anos

5. Qual o seu estado civil?

_ Solteiro

- Casado

_ Relacionamento estável

- Viúvo

_ Divorciado

6. Aproximadamente, qual é a sua renda familiar mensal?

Inferior a $\mathrm{R} \$ 937$

_ $R \$ 937$ a $R \$ 1.874$

_ $R \$ 1.874$ a $R \$ 3.748$

_ $R \$ 3.748$ a $R \$ 5.622$

$R \$ 5.622$ a $R \$ 9.370$

$R \$ 9.370$ a $R \$ 15.929$

_ Acima de $R \$ 15.929$

7. Para você, papelarias são estabelecimentos que (pode selecionar mais de uma opção):

_ Comercializam material escolar;

_ Comercializam material de escritório;

_ Comercializam produtos de pintura;

_ Comercializam itens básicos de informática;

_ Comercializam soluções para o dia-a-dia;

_ Comercializam produtos de bazar e presentes.

_ Outros (especifique) 
8. Em que situações você vai a uma papelaria (pode selecionar mais de uma opção)?

_ Quando vou comprar material escolar;

_Quando sinto necessidade de algum produto específico de papelarias;

_ Quando sou responsável pela compra de materiais administrativos para a empresa em que trabalho;

_ Quando perto de datas comemorativas/feriados em busca de presentes;

_ Quando perto de datas comemorativas/feriados em busca de itens para consumo próprio;

_ Quando procuro presentear alguém sem motivo específico;

_Quando procuro variedade de produtos;

_ Quando a vitrine me chama atenção;

_ Quando procuro produtos que vi em alguma propaganda;

_ Outros (especifique)

9. Quando você pensa em ir a uma papelaria, prefere:

_ Procurar em um shopping, por um pequeno varejista;

_ Procurar em um shopping, por um grande varejista;

_ Procurar, na rua, um estabelecimento de pequeno varejo próximo;

_ Procurar, na rua, um estabelecimento de grande varejo próximo;

_ Procurar no local mais próximo (rua ou shopping) por um pequeno varejista;

_ Procurar no local mais próximo (rua ou shopping) por um grande varejista;

_ Procurar em qualquer local (rua ou shopping) por uma marca conhecida;

_ Procurar em qualquer local (rua ou shopping) por um pequeno varejista;

_ Procurar em qualquer local (rua ou shopping) por um grande varejista;

_ Procurar por qualquer tipo de varejo, desde que seja próximo;

- Procurar por qualquer tipo de varejo, desde que atenda às minhas necessidades. 
10. Quando vai à uma papelaria, o que você considera importante (pode selecionar mais de uma opção)?

_ Bom atendimento

- Preço

_ Variedade de produtos

_ Localização

_ Tempo gasto

_ Personalização dos serviços

- Ambiente

_ Facilidade de acesso

_ Conhecimento dos vendedores sobre os produtos oferecidos

_ Outro (especifique)

11. Classifique os atributos anteriores em grau de importância: (sendo 1 para o mais importante e 9 para o menos importante):

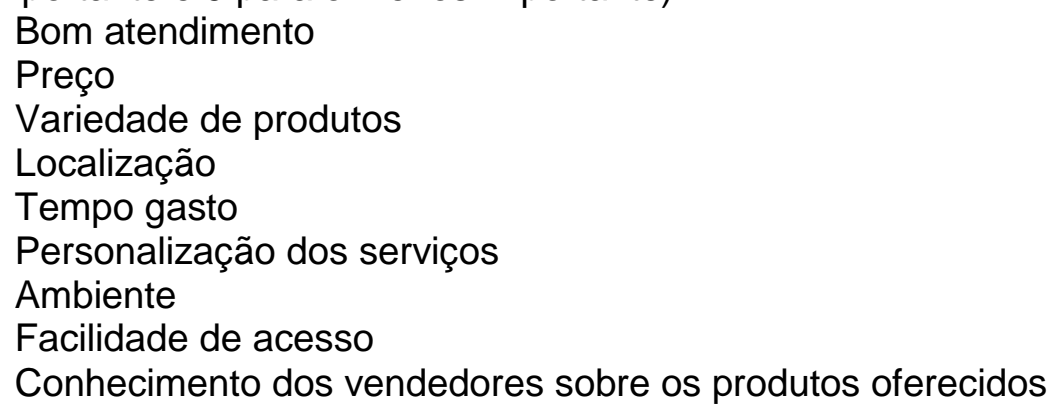

12. Convive com pessoas que frequentam a escola?

_ Sim, tenho filho(s) que frequentam o colégio.

_ Sim, tenho irmão(s) que frequentam o colégio.

_ Sim, tenho membro(s) da família, amigo(s) ou afilhados (as) que frequentam o colégio.

_ Não tenho relacionamento próximo com pessoas que frequentam o colégio.

_ Não tenho nenhum tipo de relacionamento com pessoas que frequentam o colégio. 